\title{
Induction of ketosis in rats fed low-carbohydrate, high-fat diets depends on the relative abundance of dietary fat and protein
}

\author{
Maximilian Bielohuby, ${ }^{1}$ Dominik Menhofer, ${ }^{1}$ Henriette Kirchner, ${ }^{2}$ Barbara J. M. Stoehr, ${ }^{1}$ \\ Timo D. Müller, ${ }^{2}$ Peggy Stock, ${ }^{3}$ Madlen Hempel, ${ }^{3}$ Kerstin Stemmer, ${ }^{2}$ Paul T. Pfluger, ${ }^{2}$ Ellen Kienzle, ${ }^{4}$ \\ Bruno Christ, ${ }^{3}$ Matthias H. Tschöp, ${ }^{2}$ and Martin Bidlingmaier ${ }^{1}$ \\ ${ }^{1}$ Endocrine Research Unit, Medizinische Klinik-Innenstadt, Ludwig-Maximilians University, Munich; ${ }^{2}$ Obesity Research \\ Center, Metabolic Diseases Institute, College of Medicine, University of Cincinnati, Cincinnati, Ohio; ${ }^{3}$ First Department of \\ Medicine, Molecular Hepatology Laboratory, Martin-Luther University Halle-Wittenberg, Halle, Germany; and ${ }^{4}$ Department \\ of Nutrition and Dietetics, Ludwig-Maximilians University, Munich, Germany
}

Bielohuby M, Menhofer D, Kirchner H, Stoehr BJ, Müller TD, Stock P, Hempel M, Stemmer K, Pfluger PT, Kienzle E, Christ B, Tschöp MH, Bidlingmaier M. Induction of ketosis in rats fed lowcarbohydrate, high-fat diets depends on the relative abundance of dietary fat and protein. Am J Physiol Endocrinol Metab 300: E65-E76, 2011. First published October 13, 2010; doi:10.1152/ajpendo.00478.2010.Low-carbohydrate/high-fat diets (LC-HFDs) in rodent models have been implicated with both weight loss and as a therapeutic approach to treat neurological diseases. LC-HFDs are known to induce ketosis; however, systematic studies analyzing the impact of the macronutrient composition on ketosis induction and weight loss success are lacking. Male Wistar rats were pair-fed for 4 wk either a standard chow diet or one of three different LC-HFDs, which only differed in the relative abundance of fat and protein (percentages of fatprotein in dry matter: LC-75/10; LC-65/ $20 ; \mathrm{LC}-55 / 30$ ). We subsequently measured body composition by nuclear magnetic resonance (NMR), analyzed blood chemistry and urine acetone content, evaluated gene expression changes of key ketogenic and gluconeogenic genes, and measured energy expenditure (EE) and locomotor activity (LA) during the first 4 days and after $3 \mathrm{wk}$ on the respective diets. Compared with chow, rats fed with LC-75/10, LC-65/20, and LC-55/30 gained significantly less body weight. Reductions in body weight were mainly due to lower lean body mass and paralleled by significantly increased fat mass. Levels of $\beta$-hydroxybutyate were significantly elevated feeding LC-75/10 and LC-65/20 but decreased in parallel to reductions in dietary fat. Acetone was about 16-fold higher with LC$75 / 10$ only $(P<0.001)$. In contrast, rats fed with LC-55/30 were not ketotic. Serum fibroblast growth factor-21, hepatic mRNA expression of hydroxymethylglutaryl-CoA-lyase, peroxisome proliferator-activated receptor- $\gamma$ coactivator- $1 \alpha$, and peroxisome proliferator-activated receptor- $\gamma$ coactivator $1 \beta$ were increased with LC-75/10 only. Expression of phosphoenolpyruvate carboxykinase and glucose-6-phosphatase was downregulated by $50-70 \%$ in LC-HF groups. Furthermore, EE and LA were significantly decreased in all groups fed with LC-HFDs after 3 wk on the diets. In rats, the absence of dietary carbohydrates per se does not induce ketosis. LC-HFDs must be high in fat, but also low in protein contents to be clearly ketogenic. Independent of the macronutrient composition, LC-HFD-induced weight loss is not due to increased EE and LA.

Atkins'-style diets; ketone bodies; gluconeogenesis; energy expenditure; weight loss

DURING STATES OF FASTING, secretion of ketone bodies is a pivotal metabolic process to ensure adequate fuel supply for the brain

Address for reprint requests and other correspondence: $M$. Bielohuby, Ludwig-Maximilians-Univ. Medizinische Klinik-Innenstadt Endocrine Research Unit, Ziemssenstrasse 1 80336, Munich, Germany (e-mail: Max. Bielohuby@med.uni-muenchen.de). and other tissues like muscles $(8,15)$. The process of ketogenesis involves adipocytes that break down triglycerides into glycerol and fatty acids and hepatocytes that transform the fatty acids into ketone bodies via $\beta$-oxidation. Besides fasting, production of ketone bodies can also be triggered when the carbohydrate metabolism is disturbed. Excess production of ketone bodies may occur in diabetic patients (29) when circulating insulin levels are too low to allow sufficient uptake of glucose. An induction of ketosis can be life threatening when reaching pathological levels, e.g., in diabetic ketoacidosis; however, under physiological conditions, a ketosis can provide highly beneficial effects on human health. For instance, children suffering from epilepsy receive ketogenic, very-lowcarbohydrate diets as part of their treatment $(36,38)$ to suppress the occurrence and frequency of seizures $(15,27)$. Mechanistically, ketogenic diets may modulate (50) the activity of ATP-dependent potassium channels in neurons (32) which are of importance for seizure control. Because ketogenic lowcarbohydrate, high-fat (LC-HF) diets have proven efficiency in the management of epilepsy, it has been suggested that other neurological diseases such as Alzheimer's and Parkinson's disease might also respond well to treatment with ketogenic LC-HF diets (50). Several dietary intervention trials in overweight subjects reported that LC-HF diets exert health benefits by inducing weight loss $(1,42,51)$. The concept of dieting by use of LC-HF diets has been largely promoted in past years (11), and these diet concepts are often known under the synonym "Atkins'-style" diets. The original theory behind these dietary interventions proposed that weight loss occurs first through the induction of ketosis and the associated loss of energy via excretion of ketone bodies and second also through increases in energy expenditure (5). However, this theory has since been widely rejected $(4,24)$. Also, we have previously shown that ketogenic LC-HF diet-induced energy loss via ketone bodies does not quantitatively contribute to the overall energy balance (10). In regard to energy expenditure, two recent investigations have shown that mice fed a ketogenic diet show increased energy expenditure, which could potentially explain LC-HF diet-induced weight loss $(25,26)$. Besides the ongoing discussion concerning the underlying mechanisms of weight loss with LC-HF diets, also the proposed beneficial effects of LC-HF diets on body composition have been questioned in several animal studies. Most animal studies, including our previous findings, have reported that weight loss with LC-HF diets is mainly due to loss of lean body mass. In parallel, consumption of LC-HF diets has been reported to 
increase accumulation of visceral fat $(6,11,16,26,31)$. In light of the increased interest in studying the effects of ketosis, either in regard to treatment of neurological diseases or as a potential mediator for weight loss with LC-HF diets, feeding studies using ketogenic LC-HF diets in different rodent models are frequently conducted. The commercially available ketogenic LC-HF diets are usually very high in fat but rather low in protein contents. Usage of this extreme type of diet indeed induces ketosis in rodents, and profound physiological changes associated with these ketogenic diets have been described in mice (26) and rats (13). One problem with ketogenic LC-HF diets is that it is difficult to attribute observed effects (e.g., loss of body weight) to either the presence of ketone bodies or to the normally very low protein content of these diets. The ideal ketogenic diet for research purposes would be a LC-HF diet that is ketogenic but ensures the sufficient supply of protein at the same time. However, until now, it is not clear whether the absence of dietary carbohydrates per se or the absence of carbohydrates in combination with a specific abundance of the two other macronutrients, fat and protein, is required to induce ketosis. To answer this open question, we fed rats three different LC-HF diets that only differed in their relative abundance of dietary fat and protein. All LC-HF diets used in this study had equally low carbohydrate contents (below $2 \%$ of metabolizable energy), but fat and protein levels were reciprocally balanced in $10 \%$ increments.

Besides production of ketone bodies, de novo synthesis of glucose from fat and protein in the liver (gluconeogenesis) represents the classical metabolic pathway to compensate for carbohydrate shortage. Thus, we also investigated hepatic key enzymes of gluconeogenesis in rats fed the LC-HF diets. Finally, we investigated in our rat model if LC-HF diet feeding and the induction of ketosis affect energy expenditure and locomotor activity.

\section{MATERIALS AND METHODS}

Animal husbandry. Male Wistar rats (supplied by Harlan) were housed in individual cages (artificial light, $21.5 \pm 1{ }^{\circ} \mathrm{C}$; humidity $60 \pm$ $10 \%$ ) and maintained on a $12: 12$-h light-dark cycle throughout the study (lights on at 11:00 P.M. and off at 11:00 A.M.). All animals received ad libitum access to water and standard laboratory chow $(\mathrm{CH})$ for the first 10 days following delivery to allow acclimation to the new environment. Body weight and $24-\mathrm{h}$ food intake were measured daily to the nearest $0.1 \mathrm{~g}$ (Sartorius Competence CP2201, Goettingen, Germany) $1 \mathrm{~h}$ before the onset of the dark period. At the end of the acclimation period, rats had reached an age of $12 \mathrm{wk}$ and were divided into the four diet groups ( $8-10$ rats/diet group; groups matched for body weight). Rats were then pair-fed on an isoenergetic basis to the control chow diet for 4 wk. Pair-feeding was done, since in previous ad libitum experiments, rats of the same age consumed about $20 \%$ more of the LC-HF diets (in grams). For the pair-feeding procedure, daily (ad libitum) food intake of the control chow group was measured, which allowed subsequent calculation of daily energy intake (metabolizable energy, ME) and allocation of the individual amounts of the respective LC-HF diets to the other four rat groups. By this method, all groups consumed equal amounts of energy each day. The experiments on body composition, energy expenditure (EE), and locomotor activity were performed with chow and two of the LC-HF diets; LC-75/10 and LC-55/30, at the University of Cincinnati ( $n=$ 7/diet group; male Wistar rats; Harlan). Determination of body composition (lean and fat mass) was done after 4 wk on the respective diets by a nuclear magnetic resonance (NMR) instrument developed and established for the measurement of body composition in rats
(Echo Medical Systems, Houston, TX). Body composition was measured two times in each rat, and results represent means of both measurements. All procedures described above were identical at both locations, and housing conditions in Cincinnati were adapted to only differ minimally to the ones applied at the Medizinische KlinikInnenstadt in Munich, Germany. All procedures were approved by Upper Bavarian Government's ethical committee for animal experiments and by the Institutional Animal Care and Use Committee of the University of Cincinnati.

Diet composition. Diets were purchased from Kliba Nafag (a business unit of PROVIMI KLIBA, Kaiseraugst, Switzerland). The detailed composition of each diet is shown in Table 1 . The names of the LC-HF diets used ("LC-75/10", "LC-65/20," and "LC-55/30") are related on the percentages of fat and protein in dry matter. All diets were produced as semipurified diets. The only protein source in the chow diet was sodium casein; and the only carbohydrate source was starch. Fat in the chow diet was composed of beef tallow and soy oil ( $50 \%$ each). In LC-HF diets, the only protein source used was sodium casein and the only fat source was beef tallow. The LC-HF diets contained virtually no carbohydrates, except a very little amount $(-2 \%$ of $\mathrm{ME})$ that is technically necessary to deliver minerals and vitamins. The composition of the control chow diet was chosen in analogy to the standard diet used by the American Institute of Nutrition (39). Crude fiber and crude ash contents amount to $6.7 \%$ of dry matter in the chow diet and to $12 \%$ of dry matter in LC-HF diets. Minerals and vitamins (micronutrients, crude ash) have been adapted to the respective $\mathrm{ME}$ contents of each diet. The amounts of micronutrients added were based on the AIN-93G reference diet. The macronutrient composition of each diet was independently controlled after production by Weende analysis (AGROLAB group/LUFA ITL, Kiel, Germany).

Respiratory quotient, EE, and locomotor activity. Chow-fed control rats and rats fed with two of the LC-HF diets (LC-75/10 and LC-55/ 30) were subjected to a combined indirect calorimetry system (TSE Systems, Chesterfield, MO) to simultaneously assess EE, respiratory quotient (RQ), and locomotor activity (LA). EE, RQ, and LA were assessed during the start of the experiment (i.e., the last $42 \mathrm{~h}$ of the acclimation period where all rats were still on chow and the first 4 days on the respective diets) and after $3 \mathrm{wk}$ of pair-feeding. Before each measurement, all rats ( $n=7$ /group) were allowed to acclimatize to the new cages for $24 \mathrm{~h}$. Subsequently, O2 consumption and $\mathrm{CO} 2$ production were measured every $60 \mathrm{~min}$ for a total of $144 \mathrm{~h}$ (first measurement) and $60 \mathrm{~h}$ (second measurement) to determine the $R Q$ and EE. Data on EE were normalized to the respective metabolic mass $\left(\mathrm{BW}^{0.75}\right)$ of individual rats. LA was monitored by using an infrared beam break system, as previously described (18).

Analysis of ketosis. After 25 days on the respective diets, urine and blood samples were obtained from six to eight rats of each diet group.

Table 1. Energy content (ME) and macronutrient composition of the diets used

\begin{tabular}{lcccc}
\hline \multicolumn{1}{c}{ Diet } & ME, MJ/kg dm & $\begin{array}{c}\text { Fat in dm and } \\
\text { in \% of ME }\end{array}$ & $\begin{array}{c}\text { Protein in \%dm } \\
\text { and in \% of ME }\end{array}$ & $\begin{array}{c}\text { CHO in \%dm } \\
\text { and in \% of ME }\end{array}$ \\
\hline LC-75/10 & 31.55 & $75 / 92.8$ & $10 / 5.5$ & \\
LC-65/20 & 29.18 & $65 / 86.3$ & $20 / 11.8$ & $3 / 1.7$ \\
LC-55/30 & 27.73 & $55 / 78.7$ & $30 / 19.1$ & $3 / 1.9$ \\
Chow & 17.62 & $8 / 16.7$ & $19.3 / 19$ & $66 / 64.3$ \\
\hline
\end{tabular}

The macronutrient composition is provided as a percentage of dry matter (dm) and as a percentage of metabalizable energy (ME). Sources of fat, protein, and carbohydrates are described in MATERIALS AND METHODS. Crude fiber and crude ash contents amount to $6.7 \%$ of dry matter in the chow diet and to $12 \%$ of dry matter in low-carbohydrate, high-fat (LC-HF) diets. Minerals and vitamins (crude ash) have been adapted to the respective ME contents of each diet. The amounts of micronutrients added were based on the AIN-93G reference diet. $\mathrm{CHO}$, carbohydrate. 
For collection of urine samples, rats were housed individually without bedding on stable metal grids for $6 \mathrm{~h}$. Samples for each rat were taken from 6-h cumulative urine. Directly after the collection of urine, blood samples were obtained from the tail vein. Blood samples were centrifuged, and serum was stored at $-80^{\circ} \mathrm{C}$ until analysis. Quantification of acetone in urine was performed by headspace-injection and subsequent GC-MS analysis (Laboratoriumsmedizin Dortmund, Dortmund, Germany). When acetone concentrations were below the detection limit of the method, values have been set to $1 \mathrm{mg} / \mathrm{dl}$

In serum samples, $\beta$-hydroxybutyrate $(\beta$-hydroxybutyric acid HBA) was measured by an automated system using the "Autokit 3-HB R1 and R2" (Wako Chemicals, Neuss, Germany).

Dissection of rats. After 4 wk on the respective diet, rats were fasted for $6 \mathrm{~h}$ before decapitation under isoflurane anesthesia $(n=$ $8-10 /$ diet group). Trunk blood was collected for further analysis, and centrifuged serum samples were stored at $-80^{\circ} \mathrm{C}$ until analysis. Rat were opened at the linea alba, and liver samples were collected, immediately frozen on dry ice, and finally stored at $-80^{\circ} \mathrm{C}$ until the RNA was extracted.

Measurement of free fatty acids, fasting glucose, insulin, and fibroblast growth factor-21. Free fatty acids were determined by a hal micro test (FFA Half micro test; Roche Diagnostic, Mannheim, Germany). Fasting blood glucose was measured using the glucose oxidase method (EcoSolo; Care Diagnostica, Voerde, Germany). Insulin and fibroblast growth factor-21 (FGF-21) in serum were analyzed by commercially available kits as per the manufacturer's instructions [rat ultrasensitive insulin (ALPCO, Salem, NH); rat/ mouse FGF-21 (Millipore, Billerica, MA)]

Quantitative real-time PCR of liver samples. Isolation of liver RNA was performed using the SV Total RNA Isolation System (Promega, Mannheim, Germany) following standard procedures. RNA (500 ng) was reverse transcribed into complementary cDNA in a single run applying the SuperScript III First-Strand Synthesis SuperMix for qRT-PCR (Invitrogen, Karlsruhe, Germany). Quantification of mRNA abundance was performed by real-time PCR detection using a Statagene Mx3000 instrument (Stratagene, La Jolla, CA) and EVA-green as a double-stranded DNA-specific fluorescent dye (EVA green supermix; Bio-Rad, Munich, Germany). Amplification mixes $(25 \mu \mathrm{l})$ contained $0.5 \mu \mathrm{l}$ cDNA solution, $2 \times$ SYBR Green PCR supermixes, $0.5 \mu \mathrm{l}$ of each primer $(10 \mathrm{pmol} / \mu \mathrm{l})$, and nuclease-free water. Ampli fication primers were designed using the open source software Primer3. The primer sequences used were as follows: 18S-rRNA: forward 5'-GGG AGG TAG TGA CGA AAA ATA ACA AT-3', reverse 5'-TTG CCC TCC AAT GGA TCC T-3'; hydroxymethylglutarylCoA-lyase (HMG-CoAlyase): forward $5^{\prime}$-CGG AAG AAT GTG AAC TGC TCT A-3', reverse 5'-ATG TAG ACC AGG TCC TCG GTA G-3'; peroxisome proliferator-activated receptor- $\gamma$ coactivator- $1 \alpha($ PGC- $1 \alpha)$ : forward 5'-AAT GCA GCG GTC TTA GCA CT-3', reverse 5'-GTG TGA GGA GGG TCA TCG TT-3'; peroxisome proliferator-activated receptor $\gamma$ coactivator-1 $\beta$ (PGC-1 $\beta$ ): forward 5'-CTG GCT CCT CAT CCT GTA GC-3', reverse 5- ATG TCA CCG GAG AGA TTT CG-3'; phosphoenolpyruvate carboxykinase (PCK 1): forward 5'-TGC CCT CTC CCC TTA AAA AAG-3', reverse 5'-CGC TTC CGA AGG AGA TGA TCT-3'; glucose-6phosphatase (G-6-Pase): forward 5'-CCC AGA CTA GAG ATC CTG ACA GAA T-3', reverse 5'-GCA CAA CGC TCT TTT CTT TTA CC-3'. PCR runs consisted of an initial denaturation step at $95^{\circ} \mathrm{C}$ for $5 \mathrm{~min}, 40$ cycles consisting of $10 \mathrm{~s}$ at $95^{\circ} \mathrm{C}, 30 \mathrm{~s}$ at $55^{\circ} \mathrm{C}(\mathrm{PCK} 1)$ or $60^{\circ} \mathrm{C}$ (all other primers), and $45 \mathrm{~s}$ at $72^{\circ}$ followed by a melting curve. Each PCR included duplicates of cDNA for the gene of interest, a no-template control, and five dilutions of cDNA pooled from all samples for the gene of interest and for the reference gene $18 \mathrm{~S}$ rRNA to calculate the corresponding amplification efficiency $\left[\mathrm{E}=10^{-(1 / b)}-1\right.$; where $b$ is the regression coefficient $]$. The parameter $\mathrm{C}_{\mathrm{T}}$ (cycle threshold) is defined as the cycle number at which fluorescence intensity exceeds a fixed threshold. Relative mRNA expression for the gene of interest (I) was calculated using the formula: $(1+$

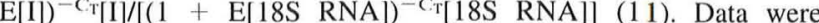
evaluated by MxPro (Stratagene) and Microsoft Excel software. All results were normalized to the expression of the housekeeping gene $18 \mathrm{~S}$ rRNA. Controls have been set to $100 \%$, and expression of LC-HF groups is shown as a percentage of chow controls.

Protein extraction and Western blots. Whole cell lysates were prepared from livers after dietary treatment. Protein extraction in radioimmunoprecipitation assay buffer and Western blot analysis has been described elsewhere (46). Blots were visualized by autoradiography. Primary antibodies used were against cytosolic PCK1 [rabbit polyclonal antibody directed against a peptide comprising the amino acids 385-399 of the rat cytosolic form (custom made by Eurogentec)] in 1:500 dilution and $\beta$-actin (Chemicon) in 1:5,000 dilution Secondary antibodies used were anti-rabbit $(1: 8,000)$ and anti-mouse $(1: 50,000)$; both were obtained from BD Biosciences (San Jose, CA)

Statistical analysis. Statistical analyses were performed using the SPSS software package (version 15.0; SPSS, Chicago, IL) and graph pad prism (GraphPad Prism, La Jolla, CA). For the statistical comparison between the dietary groups, ANOVA, with subsequent Bonferroni post hoc tests, was performed. $P$ values $<0.05$ were considered significant. In Figs. 1-6, columns labeled with different letters indicate statistically significant differences ("a" vs. "b" or "a" vs. "c"), and columns labeled with the same letter indicate that no significant difference could be found ("a" vs. "a"). All data are presented as means \pm SE.

\section{RESULTS}

Body weight gain and body composition. Rats of each diet group were matched for equal body weights at the beginning of the experiment. After $4 \mathrm{wk}$ on the respective diets, rats fed with chow gained the most, and rats fed with LC-75/10 gained the least body weight. Also, rats fed with LC-65/20 and LC-55/30 gained significantly less body weight compared with chow controls (body weight gain comparing diet day 0 and diet day 28; CH: $14.93 \pm 0.84 \%$, LC-75/10: $6.98 \pm 0.76 \%$, LC-65/20: $8.46 \pm 0.63 \%, \mathrm{LC}-55 / 30: 10.25 \pm 0.84 \% ; \mathrm{CH}$ vs. LC-75/10 and LC-65/20: $P<0.001 ; \mathrm{CH}$ vs. LC-55/30: $P<0.01$ ). The cumulative body weight gain curve for each group is shown in Fig. 1. At the end of the feeding period, total fat mass, determined by NMR scans, was significantly higher in rats fed LC-75/10 and LC-55/30 diets compared with chow controls (CH: $33.2 \pm 3.2 \mathrm{~g}, \mathrm{LC}-75 / 10: 55.5 \pm 4.0 \mathrm{~g}, \mathrm{LC}-55 / 30: 52.1 \pm$ $2.8 \mathrm{~g}$; $\mathrm{CH}$ vs. LC-75/10: $P<0.001$; $\mathrm{CH}$ vs. LC-55/30: $P<$ $0.01)$. In contrast, lean body mass was lower in rats fed

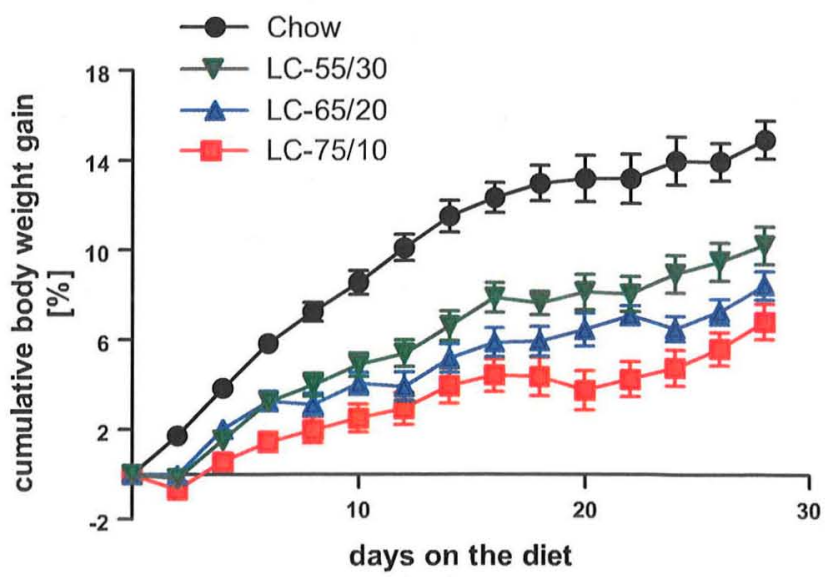

Fig. 1. Cumulative body weight gain (in \%) in rats fed chow or one of the three low-carbohydrate, high-fat (LC-HF) diets. Data are presented as means \pm SE. 
LC-75/10 and LC-55/30 diet (CH: $276.7 \pm 4.2 \mathrm{~g}, \mathrm{LC}-75 / 10$ : $256.7 \pm 5.3 \mathrm{~g}, \mathrm{LC}-55 / 30: 259.5 \pm 3.8 \mathrm{~g}$; CH vs. LC-75/10 and LC-55/30: $P<0.05$ ).

Analysis of ketosis. Rats fed the diet highest in fat (LC-75/ 10) showed the highest concentrations of HBA in serum which were about threefold higher compared with $\mathrm{CH}(P<0.001$, Fig. $2 A$ ). By reducing the fat content of the LC-HF diet by $10 \%$ (LC-65/20), serum HBA levels were approximately halved. However, serum HBA levels were still significantly increased compared with $\mathrm{CH}$ controls $(P<0.001)$. In contrast, the LC-HF diet matched in protein content to chow, LC-55/30, did not induce a significant increase in serum HBA levels $(\mathrm{CH}$ : $4.59 \pm 1 \mathrm{mg} / \mathrm{dl}$, LC-75/10: $26.86 \pm 1.1 \mathrm{mg} / \mathrm{dl}$, LC-65/20: $12.33 \pm 0.65 \mathrm{mg} / \mathrm{dl}$, LC-55/30: $6.52 \pm 0.37 \mathrm{mg} / \mathrm{dl}$; Fig. $2 A$ ). Acetone concentrations in urine were about 16-fold higher

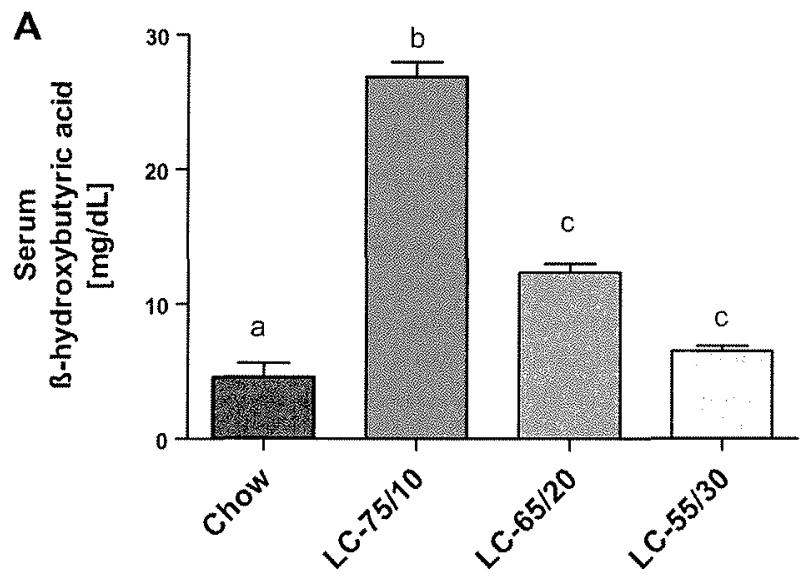

B

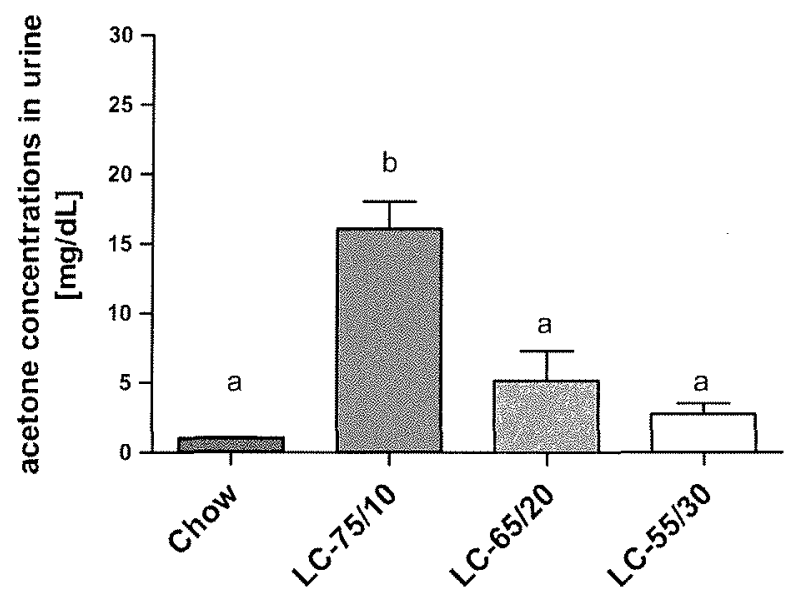

Fig. 2. Serum $\beta$-hydroxybutyric acid (HBA, $n \geq 6$ /group; $A$ ) and acetone in urine $(n \geq 6 /$ group; $B$ ). Rats fed the diet highest in fat and lowest in protein (LC-75/10) showed the highest levels of HBA $(P<0.001)$. Rats fed with the LC-65/20 diet had significantly $(P<0.001)$ higher concentrations of serum HBA compared with rats fed LC-55/30 or chow. In contrast, rats fed with LC-55/30, i.e., the LC-HF diet matched in protein content to chow, did not have higher circulating HBA. Acetone levels in urine were only significantly $(P<0.001)$ higher in the LC-75/10 group. Different letters indicate significant differences between the groups by ANOVA and subsequent Bonferroni post hoc test $(P<0.05)$. Data are presented as means $\pm \mathrm{SE}$.
$(P<0.001)$ with LC-75/10. Although acetone levels in urine were about three- to fivefold higher in LC-65/20 and LC-55/30 groups, the difference failed to reach statistical significance compared with $\mathrm{CH}$, which could be explained by the large variation within the groups (CH: $1.03 \pm 0.02 \mathrm{mg} / \mathrm{dl}, \mathrm{LC}-75 / 10$ : $16.08 \pm 1.95 \mathrm{mg} / \mathrm{dl}, \mathrm{LC}-65 / 20: 5.16 \pm 2.16 \mathrm{mg} / \mathrm{dl}, \mathrm{LC}-55 / 30$ : $2.8 \pm 0.72 \mathrm{mg} / \mathrm{dl}$; Fig. $2 B$ ). Overall, only rats fed the diet highest in fat and lowest in protein clearly were in ketosis. In sharp contrast, no signs of ketosis were detected in rats fed protein-rich LC-HF diet LC-55/30.

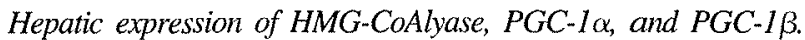
HMG-CoAlyase catalyzes the cleavage of HMG-CoA into actyl-CoA and acetoacetate. Thus, HMG-CoAlyase is a key enzyme in ketone body formation. Expression of HMG-CoAlyase mRNA in livers of rats (normalized to expression of $18 \mathrm{~S}$ rRNA) was only significantly increased after feeding LC-75/10 diet (CH: $100 \pm 10.8 \%$, LC-75/10: $193 \pm 39.7 \%$, LC-65/20: $99.9 \pm 13.4 \%$, LC-55/30: $78.9 \pm 6.9 \%$; CH vs. LC-75/10 P< 0.05 ; Fig. $3 A$ ). Hepatic expression of PGC- $1 \alpha$ and PGC-1 $\beta$ was significantly higher in rats fed LC-75/10 only (PGC-1 $\alpha$ : $\mathrm{CH}: 100 \pm 9 \%$, LC-75/10: $311.8 \pm 91.3 \%$, LC-65/20: $129 \pm$ 14.2\%, LC-55/30: $126.7 \pm 20.6 \%$; CH, LC-65/20 and LC55/30 vs. LC-75/10 $P<0.05$; Fig. 3B; PGC-1B: CH: $100 \pm$ 10.4\%, LC-75/10: $233.9 \pm 46 \%$, LC-65/20: $86.5 \pm 10.8 \%$, LC-55/30: $80.8 \pm 14.4 \%$; CH, LC-65/20 and LC-55/30 vs. LC-75/10: $P<0.01$; Fig. $3 C$ ).

Hepatic gluconeogenesis. Hepatic mRNA expression of the two key enzymes of gluconeogenesis, PCK1, and G-6-Pase was significantly reduced by $-50-70 \%$ in LC-75/10- and LC-55/30-fed rats (PCK1: $P<0.01$; G-6-Pase, CH vs. LC75/10 and LC-65/20: $P<0.05$; CH vs. LC-55/30: $P<0.001$; Fig. $4, A$ and $C$ ). Lower expression of PCK1 was confirmed by Western blot analysis of liver samples (Fig. $4 B$, row on top). No differences between the dietary groups were found for the protein expression of the reference protein/endogenous control $\beta$-actin (Fig. $4 B$, row on bottom).

Fasting glucose, insulin, $F G F-21$, and free fatty acids. Table 2 shows levels of fasting glucose, insulin, FGF-21, and free fatty acid (FFA) in rats fed $\mathrm{CH}$ or the LC-HF diets. Fasting blood glucose was lower in all LC-HF groups compared with $\mathrm{CH}$ but reached statistical significance only when comparing $\mathrm{CH}$ with LC-75/10- and LC-55/30-fed groups $(P<0.001$ and $P<$ 0.05 ). Circulating insulin was significantly lower with LC$75 / 10(P<0.01)$ but not significantly different between $\mathrm{CH}$ and LC-65/20 and LC-55/30. FGF-21 levels were significantly higher with LC75/10 compared with $\mathrm{CH}(P<0.01)$. In contrast, no significant effects on FGF-21 were detected with LC-65/20 and LC-55/30. FFA were significantly increased with LC-75/10 $(P<0.05)$ but not different between $\mathrm{CH}$ and LC-65/20 and LC-55/30 (Table 2).

Analysis of $R Q, E E$, and $L A$. We analyzed RQ, EE, and LA in rats at the beginning of the experiment (the last $42 \mathrm{~h}$ of the acclimation period and the first 4 days on the respective diets) and after $3 \mathrm{wk}$ on the respective diets. During the first 4 days on the diet, no significant changes in EE and LA were observed between chow and LC-HF groups (Fig. 5, $C$ and $E$, and Fig. 6, $A$ and $C$ ). The mean RQ was just below one with the chow diet $(0.948 \pm 0.026)$ and significantly $(P<0.001)$ lower with LC-75/10 (0.686 \pm 0.007$)$ and LC-55/30 (0.718 \pm 0.006$)$. As shown in Fig. $5 A$, the RQ declined to around 0.7 within the first $24 \mathrm{~h}$ after feeding of the respective diet. A clear circadian 
rhythmicity in RQ was only present with the chow diet (Fig. 5, $A$ and $B$ ). With each of the three diets tested, a marked light to dark phase difference was observed in EE, being significantly $(P<0.01)$ higher in the dark compared with the light phase (data after 3 wk on the respective diet; dark: $\mathrm{CH}, 5.74 \pm 0.13$, LC-75/10, $5.27 \pm 0.1$, LC-55/30, 5.52 \pm 0.11 ; light: $\mathrm{CH}$, $4.55 \pm 0.07, \mathrm{LC}-75 / 10,4.09 \pm 0.08, \mathrm{LC}-55 / 30,4.14 \pm 0.09$; all data in kcal $\cdot \mathrm{h}^{-1} \cdot \mathrm{kg}^{-0.75}$; Fig. $5, B$ and $D$ ). EE during the light and the dark phase was lower with both LC-HF diets after
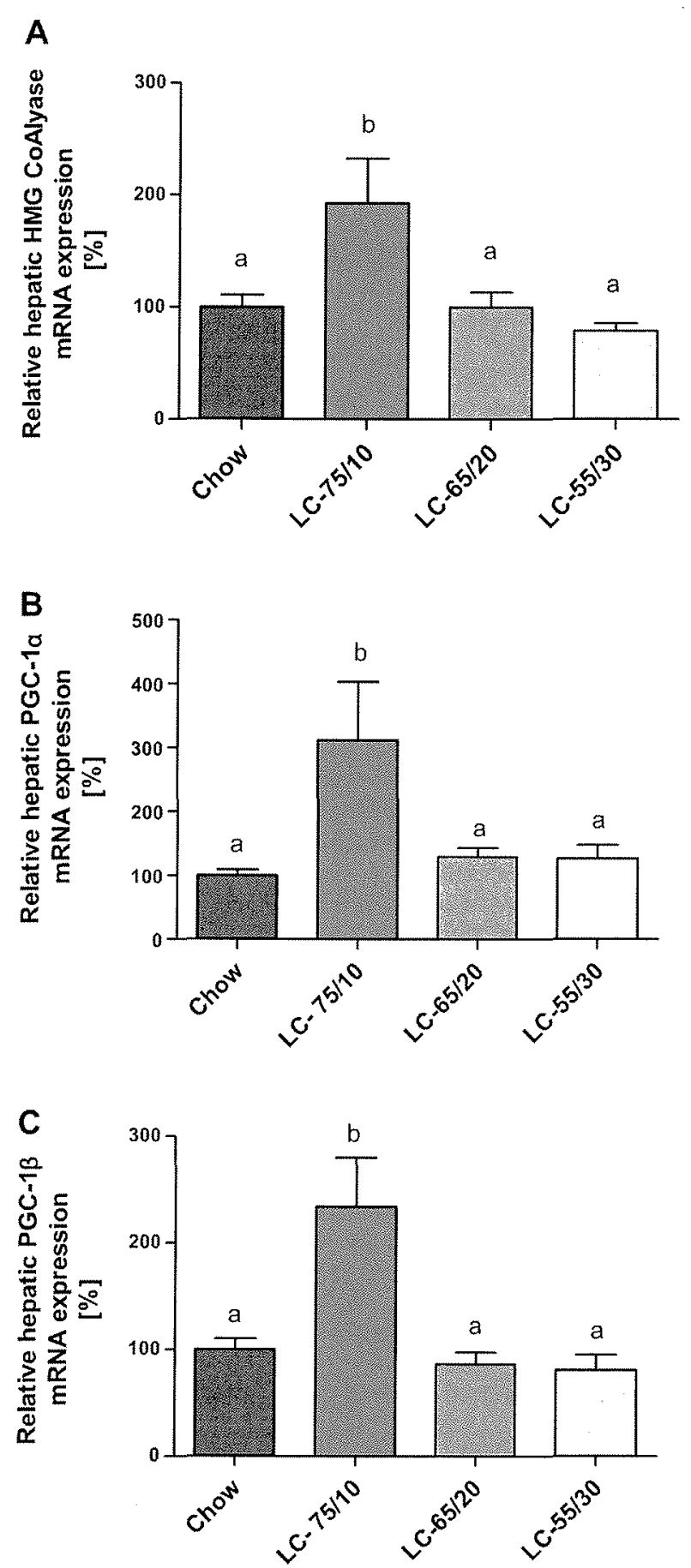

$3 \mathrm{wk}$, resulting in significantly lower total $\mathrm{EE}$ (normalized to $\mathrm{BW}^{0.75}: \mathrm{CH}, 5.03 \pm 0.08, \mathrm{LC}-75 / 10,4.57 \pm 0.06, \mathrm{LC}-55 / 30$, $4.7 \pm 0.07$; all data in $\mathrm{kcal} \cdot \mathrm{h}^{-1} \cdot \mathrm{kg}^{-0.75} ; P<0.01$ and $P<$ 0.05 ). These differences also remained statistically significant when normalized for total body weight (data not shown). In all three diet groups, LA followed a circadian pattern with high activity in the dark phase and low activity in the light phase. Rats fed both LC-HF diets for 3 wk showed a significantly lower mean of the 60-h LA measurements (CH vs. LC-75/10, $P<0.001$; CH vs. LC-55/30, $P<0.01$; Fig. $6, B$ and $D$ ). The difference between chow and LC-HF groups was more pronounced during the dark phases (data after $3 \mathrm{wk}$ on the respective diet; dark: $\mathrm{CH}, 1,199 \pm 68$ counts/h, LC-75/10, $975 \pm 43$ counts/h, LC-55/30, 1,013 +57 counts/h; light: $\mathrm{CH}, 399 \pm 19$ counts/h, LC-75/10, $279 \pm 17$ counts/h, LC-55/30, $311 \pm 20$ counts/h; Fig. $6, B$ and $D$ ).

\section{DISCUSSION}

Our study clearly shows that the absence of dietary carbohydrate per se does not trigger ketosis in rats. The three LC-HF diets analyzed only differed in their relative amounts of dietary fat and protein. Our approach of reciprocally changing fat and protein content between the diets in $10 \%$ increments clearly showed that ketosis is only robustly induced when rats are fed the diet highest in fat and lowest in protein (LC-75/10). All LC-HF groups constantly showed respiratory exchange ratios of around 0.7, which is indicative for mainly fat oxidation, thus also excluding the metabolic utilization of carbohydrates with our LC-HF diets.

Rats fed LC-HF diets with a lower fat content, but a higher amount of proteins (LC-65/20), still showed significantly higher circulating HBA levels but did not excrete acetone via urine. In contrast to the two LC-HF diets highest in fat, rats fed the LC-HF diet matched in protein to the control chow diet (LC-55/30) showed no signs of ketosis at all. For the measurement of acetone concentrations, cumulative urine was collected for at least $6 \mathrm{~h}$. In each rat of the chow diet group, acetone levels were below the detection limit of the assay. With LC-75/10 diet, acetone levels were clearly higher in all rats of that group. This was different in the two other LC-HF groups in which increased acetone levels were detectable only in some rats of each group. Of note, preliminary data from a small group of animals fed a diet in between the LC-75/10 and LC-65/20 diet (i.e., "LC-70/15") show that the difference of only $5 \%$ fat and protein between this diet and the most extreme

Fig. 3. Hepatic expression of hydroxymethylglutaryl-CoA-lyase (HMG-CoAlyase), peroxisome proliferator-activated receptor- $\gamma$ coactivator $1 \alpha$ (PGC-1 $\alpha)$, and peroxisome proliferator-activated receptor- $\gamma$ coactivator-1 $\beta$ (PGC-1 $\beta$ ) analyzed by quantitative real-time PCR $(n=8 /$ group). $A$ : mRNA expression of HMG-CoAlyase, a key enzyme in ketone body synthesis, was increased 2 -fold $(P<0.05)$ only in livers of rats fed the extreme LC-75/10 diet compared with the control chow group. PGC-1 $\alpha$ and PGC-1 13 mRNA expression in the liver was significantly upregulated only in rats fed with LC-75/10 (PGC-1 $\alpha$ : $>2$-fold, $\mathrm{CH}$ vs. LC-75/10: $P<0.05$; PGC-1 3 ; $>3$-fold, $\mathrm{CH}$ vs. LC-75/10: $P<0.01$; Fig. $3, B$ and $C$ ). Expression of HMG-CoAlyase, PGC-1 $\alpha$, and PGC- $1 \beta$ mRNA has been normalized to expression of the housekeeping gene 18S RNA. Expression levels of the genes of interest have been set to $100 \%$ in the chow group; results in the LC-HF groups are expressed as a percentage of chow. Different letters indicate significant differences between the groups by ANOVA and subsequent Bonferroni post hoc test $(P<0.05)$. Data are presented as means $\pm \mathrm{SE}$. 


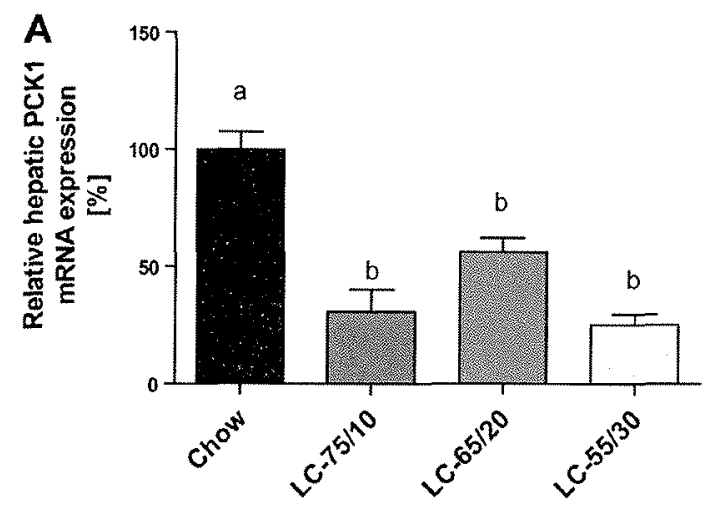

B
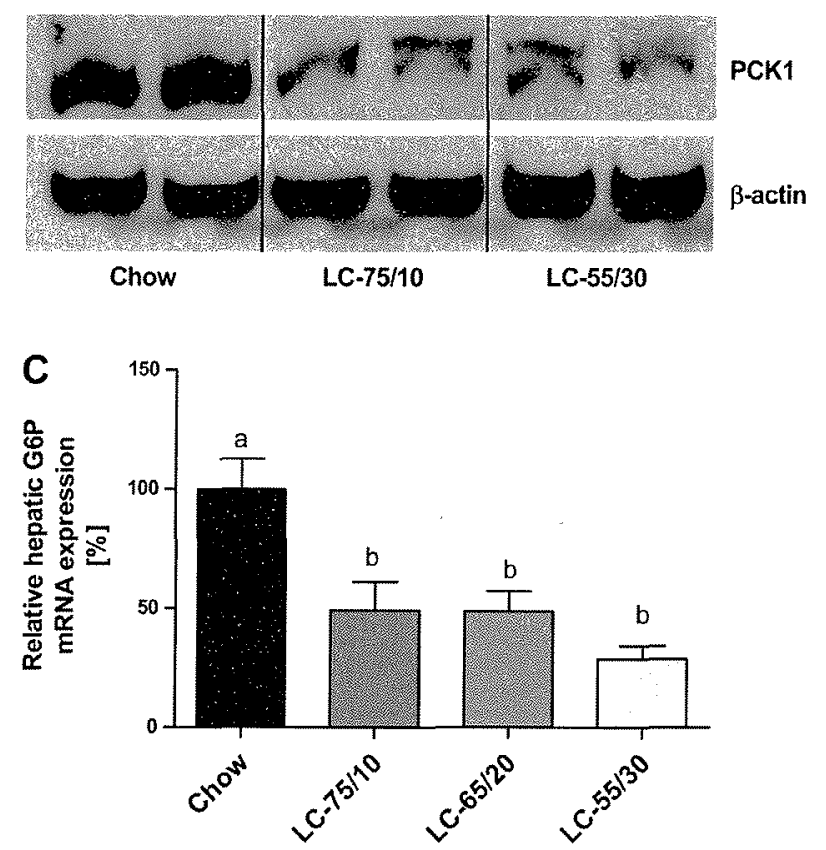

Fig. 4. Expression of key enzymes of gluconeogenesis. A: hepatic phosphoenolpyruvate carboxykinase (PCK1) mRNA expression as measured by quantitative real-time PCR ( $n=8 /$ group). $B$ : Western blot results of PCK1 (row on top) and $\beta$-actin (row on bottom) expression in the livers of rats fed chow, LC-75/10, and LC-55/30 ( $n=4$ /group). All three LC-HF diets (only 2 LC-HF diets were analyzed by Western blot) led to a downregulation of hepatic PCK1 mRNA expression by $\sim 50-70 \%(P<0.01)$. Also, hepatic glucose 6 -phosphatase [G-6-Pase (G6P)] expression was reduced by $\sim 50 \%$ in rats fed the LC-HF diets (CH vs. LC-75/10 and LC-65/20: $P<0.05, \mathrm{CH}$ vs. LC-55/30: $P<0.001 ; C$ ). Expression of PCK1 and G-6 $P$ ase $m$ RNA has been normalized to expression of the housekeeping gene 18S RNA. Expression of PCKI and G-6-Pase has been set to $100 \%$ in the chow group; results in the LC-HF groups are expressed as a percentage of chow. Different letters indicate significant differences between the groups by ANOVA and subsequent Bonferroni post hoc test $(P<0.05)$. Data are presented as means $\pm \mathrm{SE}$.

LC-75/10 diet was sufficient to significantly reduce HBA and acetone levels. Regarding the higher variation in urinary ketone body measurement compared with the rather homogeneous measurement of serum HBA, we might speculate that this was due to differences in individual drinking behavior and renal filtration rates. We therefore suggest that analysis of serum HBA is a more precise method to assess the level of ketosis in rats. Also in humans, it was suggested that measurement of HBA concentrations is more reliable than the analysis of urine to monitor ketogenic diets (49). Of note, we also analyzed ketone body concentrations in urine by commercially available dipsticks. However, these sticks, certainly intended and approved for usage in human samples only, did not reflect the laboratory results and were therefore not used for further analyses. Although the difference in urinary acetone concentrations might reach statistical significance in the LC-65/20 group if more individuals were included, the combined consideration of serum HBA, urinary acetone as well as the hepatic expression of HMG-CoAlyase and increased FGF-21 levels underline the conclusion that only rats fed the most extreme LC-75/10 diet were clearly in ketosis. In a recent review, it has been stated that there is no present consensus which cut-off limits of carbohydrates are required to induce ketosis (2). All of the LC-HF diets employed in this study had a very low carbohydrate content. Our study underlines that it is not only the carbohydrate content of LC-HF diets that determines ketosis, since the LC-HF diet matched in protein content to the control diet did not induce ketosis. Apparently, LC-HF diets must be very high in fat but consequently also low in protein to reliably induce ketosis in rats. Of note, the only diet being clearly ketogenic in this study (LC-75/10) had a protein content that was below the recommendations of the National Research Council for rat maintenance diets (37). Therefore, studies using ketogenic LC-HF diets should carefully consider if lack of protein rather than presence of ketone bodies might interfere with the observed phenotype. Our investigation shows that LC-HF diets with higher amounts of protein are not an alternative to low-protein LC-HF diets when high levels of circulating ketone bodies are desired. We have demonstrated that dietary induction of ketone body formation involves the upregulation of HMG-CoAlyase. In addition, circulating levels of FGF-21 were also significantly increased only in rats fed the LC$75 / 10$ diet. FGF-21 has been intensely discussed in its role in obesity and ketosis. Studies using FGF-21 knockout mice have shown that lack of FGF-21 inhibits production of ketone bodies (7). Our dietary model of ketosis induction shows that high levels of circulating ketone bodies are associated with high concentrations of FGF-21 in rats. Furthermore, unchanged FGF-21 levels between chow, LC-65/20, and LC-55/30 groups indicate that physiological increases in FGF-21 depend on ketosis and not on LC-HF diets per se. It has recently been shown that systemic $(17,52)$ and central $(41)$ administration of FGF-21 to rodents with diet-induced obesity can increase EE. In contrast to these previous observations, we now show that ketogenic LC-HF diet-induced increases in circulating FGF-21 do not increase EE. The discrepant findings between dietary induction of FGF-21 and exogenous treatment with FGF-21 could give further insights into the physiological role of FGF-21. Thus, it might be speculated that the physiologically inducible increases in FGF-21 are much lower than concentrations achieved by treatment. PGC- $1 \alpha$ and PGC$1 \beta$, the coactivators of the peroxisome proliferator-activated receptor- $\gamma$, have been suggested to play a key role in disorders such as obesity, diabetes, and cardiomyopathy (30). Interestingly, it has previously been shown that FGF21-deficient mice show a significantly lower hepatic expression of PGC- $1 \alpha$ and PGC-1 $\beta$. This finding strongly suggested that these two coactivators are required for FGF-21 
Table 2. Fasting glucose, insulin, FGF-21, and FFA in rats fed $\mathrm{CH}$ or the LC-HF diets

\begin{tabular}{|c|c|c|c|c|}
\hline & Fasting Glucose, mg/dl & Fasting Insulin, $\mathrm{ng} / \mathrm{ml}$ & FGF-21, pg/ml & FFA, mM \\
\hline Chow & $103.8 \pm 2.8^{a}$ & $0.69 \pm 0.06^{a}$ & $358 \pm 32^{a}$ & $0.304 \pm 0.022^{\mathrm{a}}$ \\
\hline $\mathrm{LC}-75 / 10$ & $81.6 \pm 2.1^{b}$ & $0.41 \pm 0.05^{\mathrm{b}}$ & $1139 \pm 202^{b}$ & $0.402 \pm 0.017^{\mathrm{b}}$ \\
\hline $\mathrm{LC}-65 / 20$ & $92.8 \pm 2.5^{a, b}$ & $0.55 \pm 0.07^{a, b}$ & $298 \pm 62^{: 1}$ & $0.308 \pm 0.046^{a, b}$ \\
\hline LC-55/30 & $91.2 \pm 3.8^{\mathrm{b}}$ & $0.58 \pm 0.07^{3.6}$ & $119 \pm 23^{x}$ & $0.236 \pm 0.021^{\mathrm{a}}$ \\
\hline
\end{tabular}

Data are presented as means $\pm \mathrm{SE} ; n \geq 8$ rats/group. Fasting blood glucose was lower in all LC-HF groups compared with chow (CH) but reached statistical significance only when comparing $\mathrm{CH}$ with LC-75/10 and LC-55/30 groups $(P<0.001$ and $P<0.05)$. Circulating insulin was significantly lower with LC-75/10 $(P<0.01)$ but not significantly different between $\mathrm{CH}$ and the other LC-HF groups. Serum concentrations of fibroblast growth factor $(\mathrm{FGF})-21$ were significantly higher $(P<0.01)$ in rats fed LC-75/10 compared with chow, LC-65/20, and LC-55/30. Free fatty acids (FFA) were significantly $(P<0.05)$ higher in rats fed the LC-75/10 diet. Different letters indicate significant differences between the groups by ANOVA and subsequent Bonferroni post hoc test $(P<0.05)$.

action (7). In our study, PGC- $1 \alpha$ and PGC- $1 \beta$ were selectively upregulated in livers of rats, which also showed significantly higher circulating FGF-21 concentrations. These data suggest that the hepatic PGC- $1 \alpha$ and PGC-1 $\beta$ expression may also be increased by dietary interventions that induce high FGF-21 serum levels.

Because of its ability to take up but also to release glucose, the liver has a special role in carbohydrate metabolism $(35,45)$.

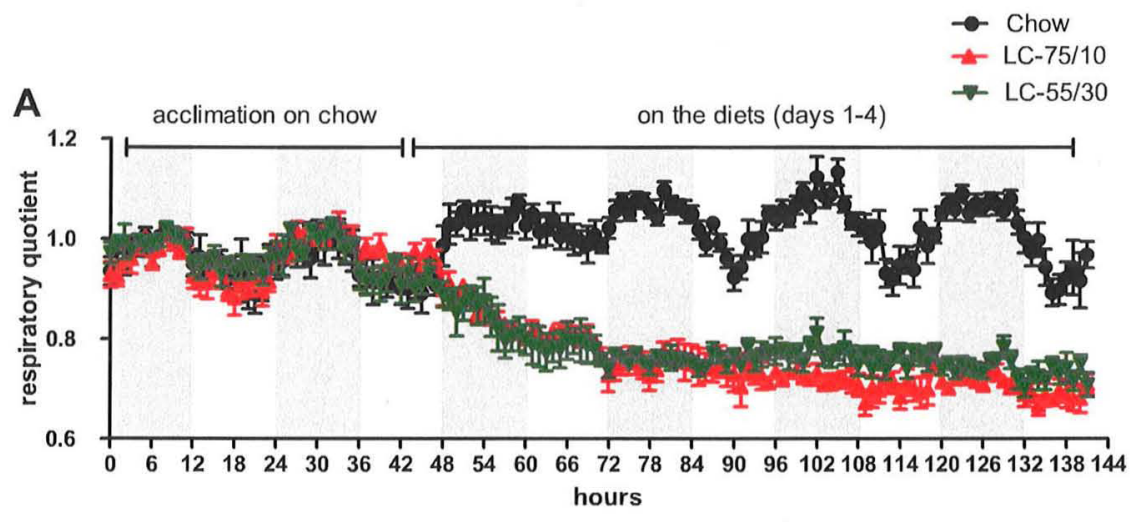

after 3 weeks on the respective diets

B
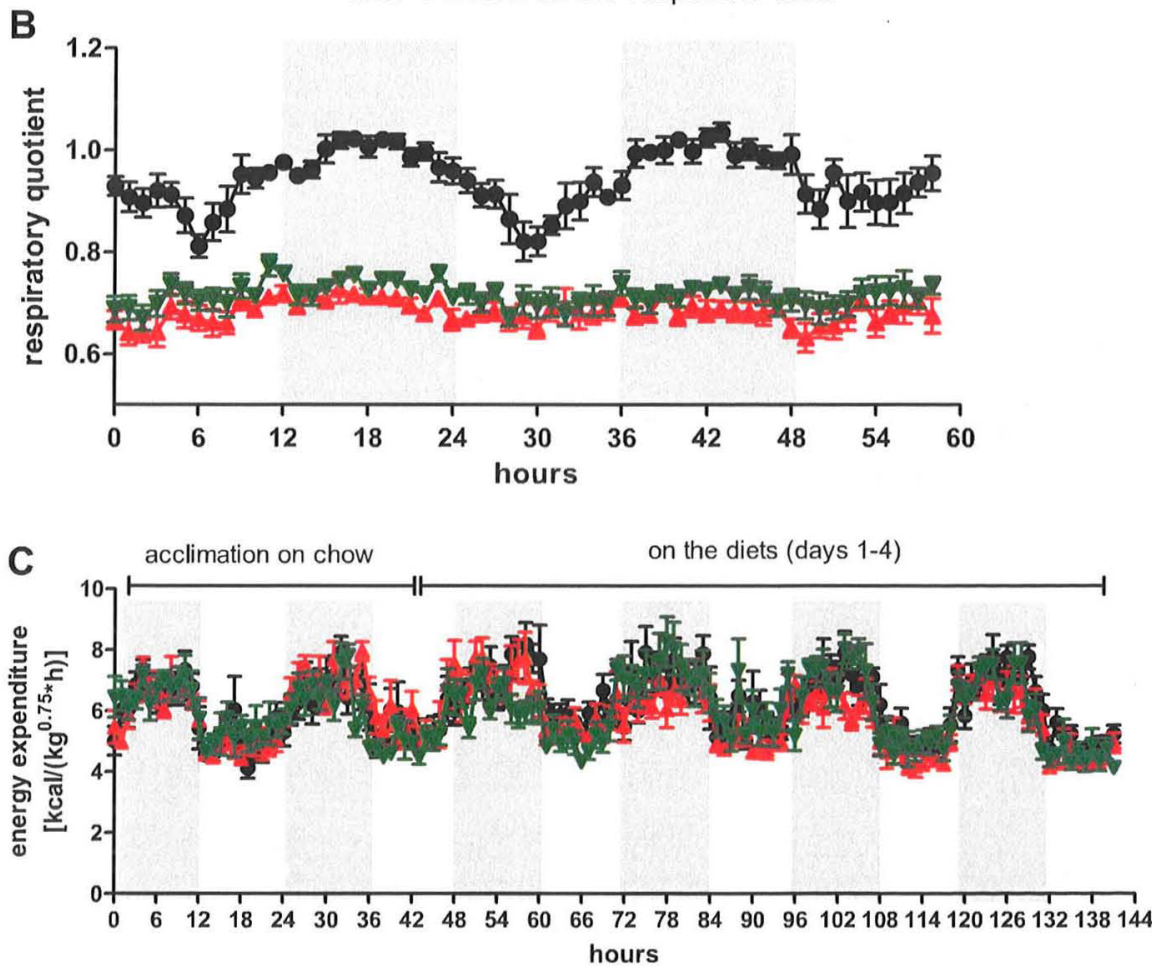

Fig. 5. Respiratory quotient (RQ, $A$ and $B$ ) and energy expenditure (EE, $C-F$ ) in rats fed chow, LC-75/10, and LC-55/30 diets ( $n=7 /$ group $)$ $A, C$, and $E$ : data for rats during acclimation on chow and the subsequent first 4 days on the respective diets. $B, D$, and $F$ : data from the same rats but after $3 \mathrm{wk}$ on the respective diets. The RQ showed a circadian rhythmicity, and 24-h means were around 1 in rats fed the chow diet, indicating predominant utilization of glucose as a fuel source. In rats fed both LC-HF diets, circadian rhythmicity was diminished. The 24-h RQ mean of both LC-HF groups was significantly lower compared with the chow (CH) group $(P<0.001)$ and dropped to $\sim 0.7$ ( $A$ and $B$ ) during the first $24 \mathrm{~h}$ after the start of the diet $(A)$, indicating predominant utilization of fat. EE showed a circadian rhythmicity with all three diets, being significantly $(P<0.001)$ higher during the dark phase $(C-F)$. EE showed no changes between the groups during the first 4 days of the experiment $(C$ and $E$ ). In contrast, mean total EE was significantly lower with both LC-HF diets compared with chow after $3 \mathrm{wk}$ on the diets (CH vs. $\mathrm{LC}-75 / 10: P<0.01, \mathrm{CH}$ vs. LC-55/30: $P<0.05$; Fig. $4 F$ ). Data on EE have been normalized to the metabolic body weight $\left(\mathrm{BW}^{0.75}\right)$. Gray bars indicate dark phases. Different letters indicate significant differences (determined by ANOVA and subsequent Bonferroni post hoc test; $P<0.05$ ). Data are presented as means \pm SE. NS, not significant. 

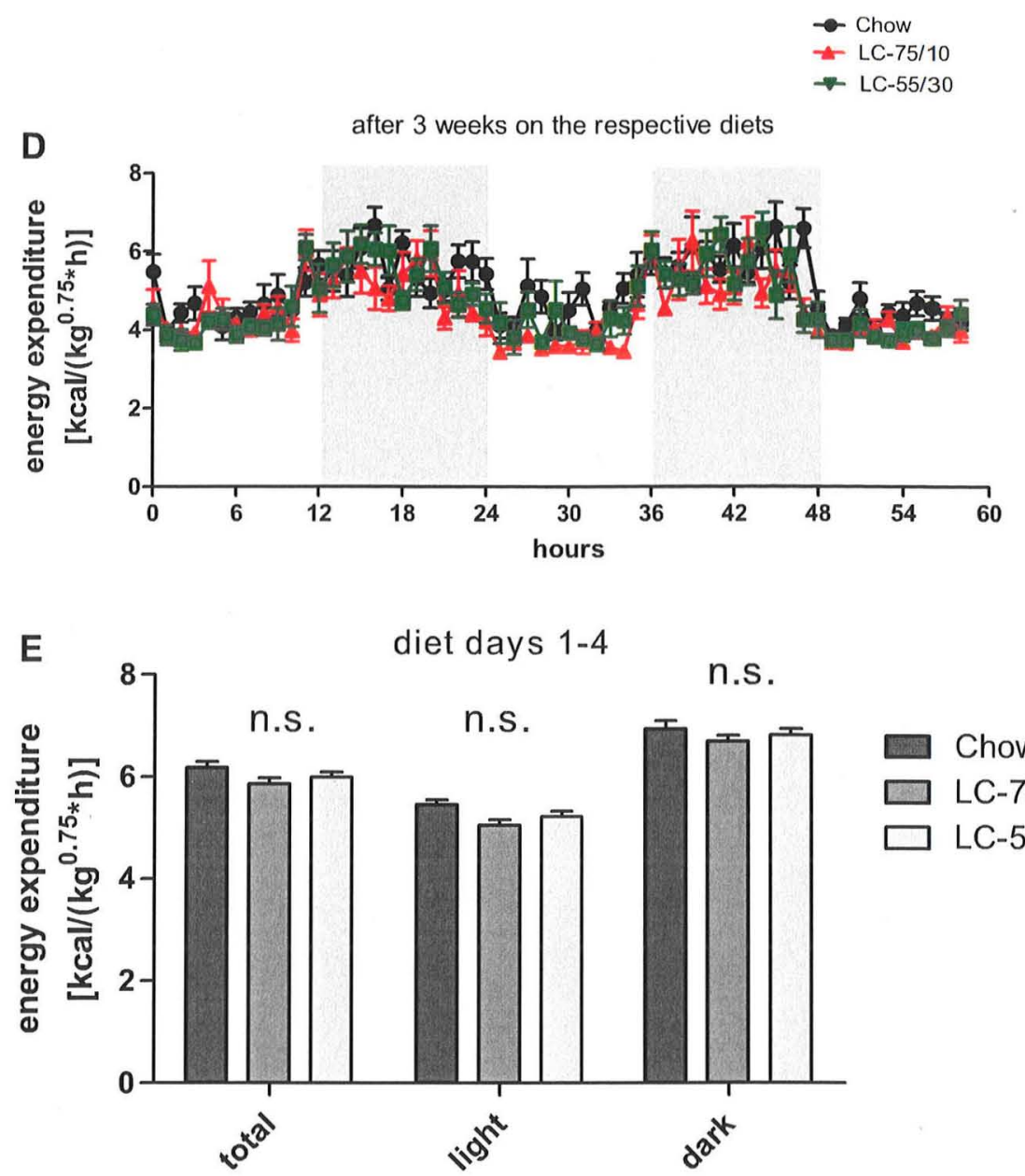

Chow

Fig. 5-Continued

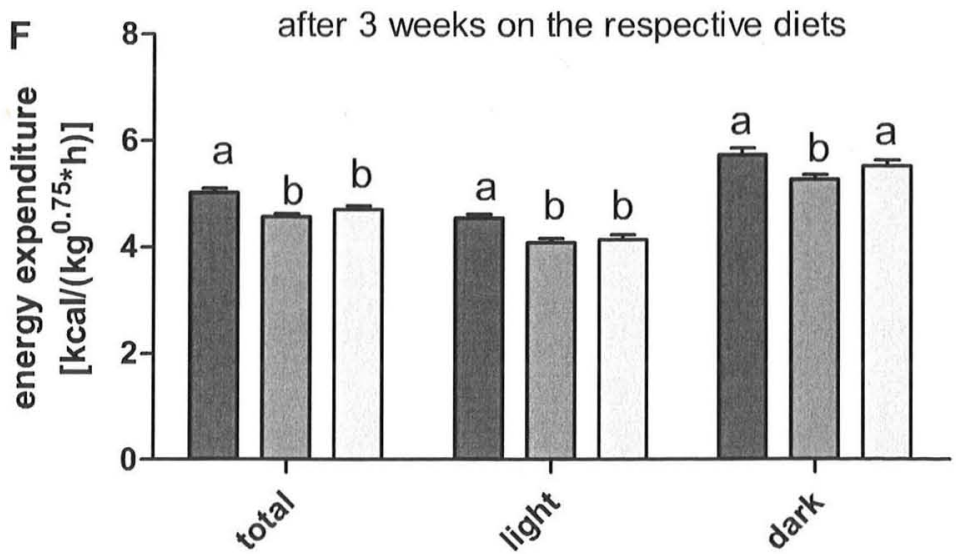

Glycogenolysis and gluconeogenesis represent the major pathways of the metabolism to react to hyper- and hypoglycemia (35). During prolonged fasting, hepatic gluconeogenesis and expression of the involved enzymes, especially PCK1 $(21,22)$, are increased, whereas, during hyperglycemia, hepatic gluconeogenesis is virtually shut off (35). Because of the low carbohydrate content in LC-HF diets, one might speculate that gluconeogenesis is increased, at least in the presence of protein. In healthy subjects, it has been shown that the dietary carbohydrate content affected the rate of postabsorptive glucose production, especially through modulation of glycogenolysis (12). In the same investigation, study subjects exposed to a very low carbohydrate diet showed $\sim 14 \%$ higher gluconeogenesis compared with subjects on a control diet (12). In an 

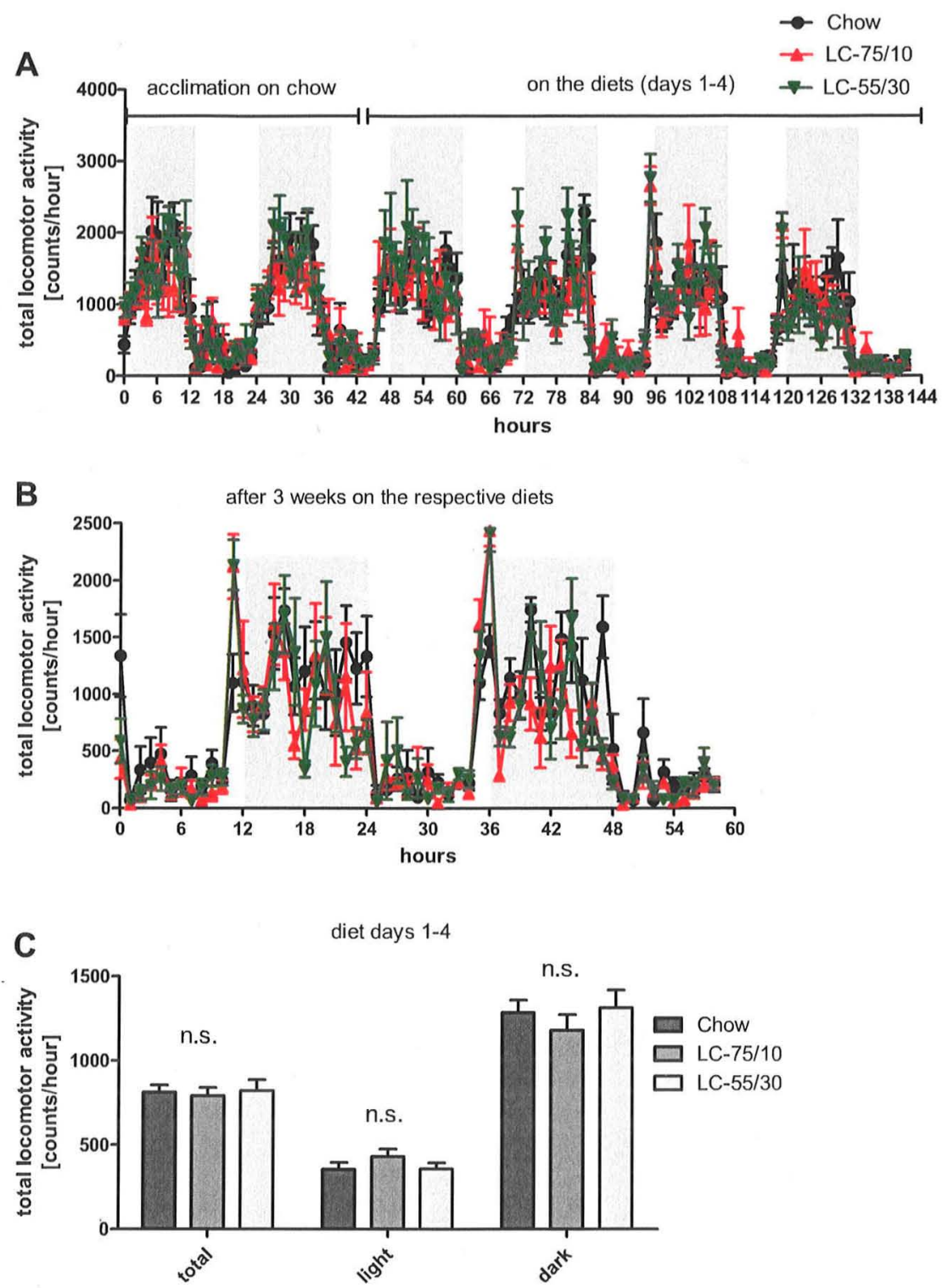

Fig. 6. Locomotor activity in rats fed chow, LC-75/ 10 , and LC-55/30 diets ( $n=7 /$ group) during acclimation and the first 4 days on the respective diets $(A$ and $C$ ) and after 3 wk on the respective diets ( $B$ and $D)$. Locomotor activity was significantly higher during the dark phase in all three diet groups $(P<$ 0.001 ). No significant differences between chow and both LC-HF diets were observed during the acclimation period or during the first 4 days on the respective diets ( $A$ and $C$ ). After 3 wk, rats fed both LC-HF diets showed a significantly lower mean locomotor activity during the $60 \mathrm{~h}$ of measurement $(\mathrm{CH}$ vs. LC-75/10, $P<0.001$; CH vs. LC-55/30, $P<0.01$ $B$ and $D$ ). The difference between $\mathrm{CH}$ and $\mathrm{LC}-\mathrm{HF}$ groups was more pronounced during the dark phases. Gray bars indicate dark phases. Different letters indicate significant differences (determined by ANOVA and subsequent Bonferroni post hoc test; $P<0.05$ ). Data are presented as means $\pm \mathrm{SE}$.

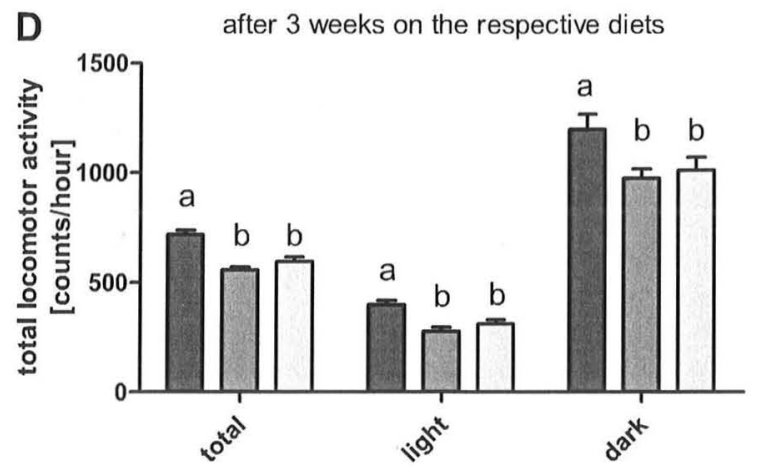


earlier study, hepatic gluconeogenesis was also increased after feeding a high-protein, carbohydrate-free diet to rodents (19, $20)$. In contrast to these previous investigations and although fasting glucose levels were significantly lower with LC-75/10 and LC-55/30 diets, our real-time PCR and Western blot data have shown that key enzymes required for hepatic gluconeogenesis are significantly downregulated in rats fed the LC-HF diets. This effect was independent of the presence of ketone bodies and of the amount of dietary protein in the LC-HF diet. Interestingly, with LC-75/10 and LC-55/30 diets, fasting glucose levels were significantly lower compared with chow (Table 2). The observed downregulation of hepatic expression of PCK1 and G-6-Pase seems to be a specific feature of LC-HF diets, since no differences were observed between the chow group and rats that were fed a standard high-fat, normalcarbohydrate "cafeteria" diet (data not shown). One possible explanation for the discrepant findings could derive from the observation that fatty acids inhibit gluconeogenesis $(21,44)$. However, in our study, only rats fed the extreme LC-75/10 diet showed increased levels of FFA (Table 2). Another possible explanation is that a 4-wk exposure to LC-HF diets has different effects on metabolism and gluconeogenesis than the very short-term diet exposures used in the other studies. In our study, rats fed both LC-HF diets showed a significant accumulation of lipid droplets in livers (Sudan III staining, data not shown); thus, the capacity of the liver to perform gluconeogenesis might be impaired. In humans, several reports have shown that LC-HF diets are effective in reducing body weight loss (42). Although never proven in scientific studies, part of the original theory behind the mechanism of LC-HF diets was induction of ketosis and loss of energy through excretion of ketone bodies. However, this theory was criticized soon after publication $(3,4,24)$. In a recent study, weight loss in obese subjects was similar between two groups, one consuming a low-carbohydrate diet the other group a diet high in carbohydrate content (23). Therefore, mechanisms like an increased overall health awareness, willingness to exercise (9), and reduced food choice and palatability may explain the observed weight loss in dieters. As we have shown previously $(11,16)$, and also demonstrate in this study, pair-feeding of rats with LC-HF diets indeed leads to reductions in body weight gain. However, reduced body weight gain with LC-HF diets was mainly due to a reduction in fat-free lean body mass. The NMR data obtained in this study for chow, LC-75/10, and LC-55/30 groups confirmed our previous findings that LC-HF diets lead to accumulation of visceral fat and that reductions in body weight are mainly due to reductions in lean body mass with LC-HF diets (11). Measurements of fat pad weights and lean body mass at the dissection have also shown this in all groups, including rats fed the LC-65/20 diet. Other groups have studied LC-HF diets in animal models employing different feeding regiments but found similar effects on body composition, i.e., increases in fat mass and decreased lean body mass $(6,26,31,33)$. Therefore, our own and previously published data in different animal models suggest that LC-HF diets are not beneficial for body composition, regardless of the presence of ketone bodies.

LC-HF diets as used for dietary purposes in humans have a much lower fat but higher protein and carbohydrate content than the extreme LC-75/10 diet we used in our rat model. Although the mechanisms of ketogenesis might differ between humans and rats, our findings question whether people per- forming Atkins'-style diets being rather moderate in fat content actually reach a constant state of ketosis. Similarly, it has recently been reported that a very low-carbohydrate/high-fat/ high-protein Atkins-type diet is only marginally ketogenic in mice (34). Regardless of the occurrence of diet-induced ketosis in humans, one has to ask if the energy loss via ketone bodies in urine can quantitatively contribute significantly to the overall energy balance. In a recent study analyzing digestibility of different diets, we measured the amounts of gross energy in feces and urine from rats fed a ketogenic LC-HF diet by bomb calorimetry. The results have shown that 24 -h energy loss through feces and urine account for only $\sim 0.8-1 \%$ of daily energy intake in rats fed a ketogenic LC-HF diet (data not shown and Ref. 10). Therefore, energy loss through ketone bodies in feces and urine did not quantitatively contribute to the overall energy balance. We speculated that ketosis could lead to increased EE and LA. In contrast, the opposite was the case, and EE and LA were even lower in rats fed the LC-HF diets. The observed reductions in LA during the dark phase could also be due to an altered eating behavior of the LC-HF groups, since it is known that the central mechanism associated with eating behavior can affect LA $(40,47,48)$. Interestingly, investigations in humans have shown that study subjects consuming LC-HF diets often feel tired and exhausted (14), which potentially could lead to reduced LA. At present, there are no comparable studies regarding LC-HF diets and LA in rats. Studies in rats employing high-fat, "normal" carbohydrate contents did not affect LA (28). Therefore, the effects we observed could be specific for low-carbohydrate diets. A possible explanation for decreased EE with both LC-HF groups might be consideration of heat increment. After consumption of a diet, heat production, and thereby also EE, depends on the macronutrient composition of the diet. Dietary proteins and carbohydrates lead to a higher heat production after food consumption than dietary fats (43). Because the LC-HF diets lack carbohydrates, lower EE might also be a result of reduced heat increment. The reduction in EE in rats fed the LC-HF diets was very small. However, our data clearly show both, that EE and LA are not increased by LC-HF diets. In summary, our study clearly shows that the absence of dietary carbohydrates per se does not induce ketosis in rats. Our LC-HF diet LC-55/ 30 , with a fat-to-protein ratio of 1.8 , did not trigger ketosis. LC-HF diets should therefore contain a very high amount of fat to robustly increase circulating levels of ketone bodies. Decreasing the amount of fat but increasing the protein content in LC-HF diets leads to lower levels of circulating ketone bodies. However, care should be taken when using LC-HF diets to avoid unwanted effects of protein malnutrition in the experiment. Independent of the macronutrient composition, rats fed the LC-HF diets did not compensate for the lack of carbohydrates by higher hepatic gluconeogenesis. Furthermore, we could show that LC-HF diets lead to a mild but significant reduction in EE and LA. Therefore, increases in $\mathrm{EE}$ are unlikely to explain the observed weight loss when dieting with LC-HF diets.

\section{ACKNOWLEDGMENTS}

We thank Juliane Ramisch (Medizinische Klinik -Innenstadt) and Jenna Holland (University of Cincinnati) for excellent technical assistance.

\section{DISCLOSURES}

All authors have no conflicts of interest. 


\section{REFERENCES}

1. Acheson KJ. Carbohydrate for weight and metabolic control: where do we stand? Nutrition 26: $141-145,2010$.

2. Adam-Perrot A, Clifton P, Brouns $\mathbf{F}$. Low-carbohydrate diets: nutri tional and physiological aspects. Obes Rev 7: 49-58, 2006

3. American Medical Association. A critique of low-carbohydrate ketogenic weight reduction regimens. A review of Dr Atkins' diet revolution. J Am Med Assoc 224: 1415-1419, 1973

4. Astrup A, Meinert Larsen T, Harper A. Atkins and other low-carbohydrate diets: hoax or an effective tool for weight loss? Lancet 364 $897-899,2004$.

5. Atkins R. Dr. Atkins New Diet Revolution. New York, NY: Avon Books, 1992.

6. Axen KV, Axen K. Very low-carbohydrate versus isocaloric high-carbohydrate diet in dietary obese rats. Obesity Silver Spring 14: 1344-1352, 2006.

7. Badman MK, Koester A, Flier JS, Kharitonenkov A, Maratos-Flier E Fibroblast growth factor 21-deficient mice demonstrate impaired adaptation to ketosis. Endocrinology 150: 4931-4940, 2009.

8. Badman MK, Pissios P, Kennedy AR, Koukos G, Flier JS, MaratosFlier E. Hepatic fibroblast growth factor 21 is regulated by PPARalpha and is a key mediator of hepatic lipid metabolism in ketotic states. Cell Metab 5: $426-437,2007$

9. Bielohuby M, Bidlingmaier M. Hunt-ing, not drive-in! An evolutionary conserved linkage between hunger and locomotion. Obesity Metab 4: 1-3, 2008.

10. Bielohuby $\mathbf{M}$, Bodendorf $\mathbf{K}$, Brandstetter $\mathbf{H}$, Bidlingmaier $\mathbf{M}$, Kienzle E. Predicting metabolisable energy in commercial rat diets: physiological fuel values may be misleading. $B r J$ Nutr 103: 1525-1533, 2010.

11. Bielohuby M, Matsuura M, Herbach N, Kienzle E, Slawik M, Hoeflich A, Bidlingmaier M. Short-term exposure to low-carbohydrate, high-fat diets induces low bone mineral density and reduces bone formation in rats. I Bone Miner Res 25: 275-284, 2010

12. Bisschop PH, Pereira Arias AM, Ackermans MT, Endert E, Pijl H Kuipers F, Meijer AJ, Sauerwein HP, Romijn JA. The effects of carbohydrate variation in isocaloric diets on glycogenolysis and gluconeogenesis in healthy men. $J$ Clin Endocrinol Metab 85: 1963-1967, 2000.

13. Bough KJ, Eagles DA. A ketogenic diet increases the resistance to pentylenetetrazole-induced seizures in the rat. Epilepsia 40: 138-143, 1999.

14. Burke LM, Hawley JA, Angus DJ, Cox GR, Clark SA, Cummings NK, Desbrow B, Hargreaves M. Adaptations to short-term high-fat diet persist during exercise despite high carbohydrate availability. Med Sci Sports Exerc 34: 83-91, 2002

15. Carmant L. Assessing ketosis: approaches and pitfalls. Epilepsia 49 , Suppl 8: 20-22, 2008.

16. Caton SJ, Yinglong B, Burget L, Spangler LJ, Tschop MH, Bidlingmaier M. Low-carbohydrate high-fat diets: regulation of energy balance and body weight regain in rats. Obesity Silver Spring 17:283 289, 2009

17. Coskun T, Bina HA, Schneider MA, Dunbar JD, Hu CC, Chen Y, Moller DE, Kharitonenkov A. Fibroblast growth factor 21 corrects obesity in mice. Endocrinology 149: 6018-6027, 2008

18. Day JW, Ottaway N, Patterson JT, Gelfanov V, Smiley D, Gidda J, Findeisen H, Bruemmer D, Drucker DJ, Chaudhary N, Holland J Hembree J, Abplanalp W, Grant E, Ruehl J, Wilson H, Kirchner H, Lockie SH, Hofmann S, Woods SC, Nogueiras R, Pfluger PT, PerezTilve D, DiMarchi $\mathbf{R}$, Tschop MH. A new glucagon and GLP-1 coagonist eliminates obesity in rodents. Nat Chem Biol 5: 749-757, 2009.

19. Eisenstein AB, Strack I, Steiner A. Glucagon stimulation of hepatic gluconeogenesis in rats fed a high-protein, carbohydrate-free diet. Metab olism 23: 15-23, 1974

20. Eisenstein AB, Strack I, Steiner A. Increased hepatic gluconeogenesis without a rise of glucagon secretion in rats fed a high fat diet. Diabetes 23 : $869-875,1974$

21. Hanson RW, Garber AJ. Phosphoenolpyruvate carboxykinase. 1. Its role in gluconeogenesis. Am J Clin Nutr 25: 1010-1021, 1972.

22. Hanson RW, Reshef L. Glyceroneogenesis revisited. Biochimie 85 $1199-1205,2003$

23. Hernandez TL, Sutherland JP, Wolfe P, Allian-Sauer M, Capell WH, Talley ND, Wyatt HR, Foster GD, Hill JO, Eckel RH. Lack of suppression of circulating free fatty acids and hypercholesterolemia during weight loss on a high-fat, low-carbohydrate diet. Am J Clin Nutr 91: $578-585,2010$
24. Hirschel Dr B. Atkins' dietetic revolution: a critique. Schweiz Med Wochenschr 107: 1017-1025, 1977.

25. Jornayvaz FR, Jurczak MJ, Lee HY, Birkenfled AL, Frederick DW Zhang D, Zhang XM, Samuel VT, Shulman GI. A high-fat, ketogenic diet causes hepatic insulin resistance in mice despite increasing energy expenditure and preventing weight gain. Am J Physiol Endocrinol Metab. doi: 10.1152/ajpendo.00361.2010.

26. Kennedy AR, Pissios P, Otu H, Roberson R, Xue B, Asakura K Furukawa N, Marino FE, Liu FF, Kahn BB, Libermann TA, MaratosFlier E. A high-fat, ketogenic diet induces a unique metabolic state in mice. Am J Physiol Endocrinol Metab 292: E1724-E1739, 2007.

27. Kossoff EH, Dorward JL. The modified Atkins diet. Epilepsia 49, Suppl 8: $37-41,2008$

28. Lapachet RA, Miller WC, Arnall DA. Body fat and exercise endurance in trained rats adapted to a high-fat and/or high-carbohydrate diet. $J$ Appl Physiol 80: 1173-1179, 1996.

29. Li L, Yang G, Ning H, Yang M, Liu H, Chen W. Plasma FGF-21 levels in type 2 diabetic patients with ketosis. Diabetes Res Clin Pract 82: 209-213, 2008.

30. Liang H, Ward WF. PGC-lalpha: a key regulator of energy metabolism Adv Physiol Educ 30: 145-151, 2006

31. Lobley GE, Bremner DM, Holtrop G, Johnstone AM, Maloney C. Impact of high-protein diets with either moderate or low carbohydrate on weight loss, body composition, blood pressure and glucose tolerance in rats. Br J Nutr 97: 1099-1108, 2007.

32. Ma W, Berg J, Yellen G. Ketogenic diet metabolites reduce firing in central neurons by opening K(ATP) channels. J Neurosci 27: 3618-3625, 2007.

33. McCargar LJ, Baracos VE, Clandinin MT. Influence of dietary carbohydrate-to-fat ratio on whole body nitrogen retention and body composition in adult rats. $J$ Nutr 119: 1240-1245, 1989.

34. Mobbs CV, Mastaitis J, Yen K, Schwartz J, Mohan V, Poplawski M Isoda F. Low-carbohydrate diets cause obesity, low-carbohydrate diets reverse obesity: a metabolic mechanism resolving the paradox. Appetite 48: 135-138, 2007.

35. Moore MC, Connolly CC, Cherrington AD. Autoregulation of hepatic glucose production. Eur J Endocrinol 138: 240-248, 1998.

36. Muzykewicz DA, Lyczkowski DA, Memon N, Conant KD, Pfeifer HH Thiele EA. Efficacy, safety, and tolerability of the low glycemic index treatment in pediatric epilepsy. Epilepsia 50: 1118-1126, 2009.

37. National Research Council. Nutrient Requirements of Laboratory Animals. Washington, D C: The National Academic Press, 1995.

38. Papandreou D, Pavlou E, Kalimeri E, Mavromichalis I. The ketogenic diet in children with epilepsy. Br J Nutr 95: 5-13, 2006.

39. Reeves PG, Nielsen FH, Fahey GC Jr. AIN-93 purified diets fo laboratory rodents: final report of the American Institute of Nutrition ad hoc writing committee on the reformulation of the AIN-76A rodent diet. $J$ Nutr 123: 1939-1951, 1993.

40. Sakkou M, Wiedmer P, Anlag K, Hamm A, Seuntjens E, Ettwiller L, Tschop MH, Treier M. A role for brain-specific homeobox factor Bsx in the control of hyperphagia and locomotory behavior. Cell Metab 5 : $450-463,2007$.

41. Sarruf DA, Thaler JP, Morton GJ, German J, Fischer JD, Ogimoto K, Schwartz MW. Fibroblast growth factor 21 action in the brain increases energy expenditure and insulin sensitivity in obese rats. Diabetes 59: $1817-1824,2010$

42. Shai I, Schwarzfuchs D, Henkin Y, Shahar DR, Witkow S, Greenberg I, Golan R, Fraser D, Bolotin A, Vardi H, Tangi-Rozental O, ZukRamot R, Sarusi B, Brickner D, Schwartz Z, Sheiner E, Marko R, Katorza E, Thiery J, Fiedler GM, Bluher M, Stumvoll M, Stampfer MJ. Weight loss with a low-carbohydrate, Mediterranean, or low-fat diet. N Engl J Med 359: 229-241, 2008.

43. Smith RR, Rumsey GL, Scott ML. Heat increment associated with dietary protein, fat, carbohydrate and complete diets in salmonids: comparative energetic efficiency. $J$ Nutr 108: 1025-1032, 1978.

44. Soling HD, Willms B, Kleineke J, Gehlhoff M. Regulation of gluconeogenesis in the guinea pig liver. Eur J Biochem 16: 289-302, 1970.

45. Soskin S, Essex HE, Herrick JF, Mann FC. The mechanism of the regulation of blood sugar by the liver. Am J Physiol 124: 558-567, 1938 .

46. Stock P, Monga D, Tan X, Micsenyi A, Loizos N, Monga SP. Plateletderived growth factor receptor-alpha: a novel therapeutic target in human hepatocellular cancer. Mol Cancer Ther 6: 1932-1941, 2007.

47. Tang-Christensen $M$, Vrang N, Ortmann S, Bidlingmaier $M$, Horvath TL, Tschop M. Central administration of ghrelin and agouti-related 
protein (83-132) increases food intake and decreases spontaneous locomotor activity in rats. Endocrinology 145: 4645-4652, 2004.

48. Tung YC, Rimmington D, O'Rahilly S, Coll AP. Pro-opiomelanocortin modulates the thermogenic and physical activity responses to high-fat feeding and markedly influences dietary fat preference. Endocrinology 148: 5331-5338, 2007.

49. van Delft R, Lambrechts D, Verschuure P, Hulsman J, Majoie M Blood beta-hydroxybutyrate correlates better with seizure reduction due to ketogenic diet than do ketones in the urine. Seizure 19: 36-39, 2010.
50. Waltz E. Epilepsy controlled by low-carb diet's effect on brain channels. Nat Med 13: 516-517, 2007

51. Wylie-Rosett J, Davis NJ. Low-carbohydrate diets: an update on current research. Curr Diab Rep 9: 396-404, 2009.

52. Xu J, Lloyd DJ, Fale C, Stanislaus S, Chen M, Sivits G, Vonderfecht S, Hecht R, Li YS, Lindberg RA, Chen JL, Jung DY, Zhang Z, Ko HJ, Kim JK, Veniant MM. Fibroblast growth factor 21 reverses hepatic steatosis, increases energy expenditure, and improves insulin sensitivity in diet-induced obese mice. Diabetes 58: 250-259, 2009. 